\title{
Resting Discharge and Response Dynamics of Horizontal Semicircular Canal Afferents of the Toadfish, Opsanus tau
}

\author{
R. Boyle ${ }^{1,3}$ and S. M. Highstein 2,3 \\ 'Departments of Otolaryngology and Physiology, Oregon Health Sciences University, Portland, Oregon 97201, \\ 'Departments of Otolaryngology and Anatomy and Neurobiology, Washington University School of Medicine, St. Louis, \\ Missouri 63110, and ${ }^{3}$ Marine Biological Laboratory, Woods Hole, Massachusetts 02543
}

\begin{abstract}
The response dynamics of 66 primary afferents of the horizontal semicircular canal were studied in the toadfish using sinusoidal, rotational stimuli from $0.001-10 \mathrm{~Hz}$ at amplitudes of $5-100 \% / s e c$. Twelve afferents were also tested to constant velocity trapezoids. Responses to sinusoids were used to classify afferents into 3 broad groups: (1) low-gain afferents that maintain a relatively linear response re: stimulus velocity across most of the frequency and amplitude spectra tested; (2) high-gain afferents that have a velocity sensitivity but also show a high-frequency gain enhancement and phase advance; and (3) so-called acceleration afferents that have a response more in phase with stimulus acceleration than velocity across the tested bandwidth. The afferent's background discharge was examined in relation to its rotational response. Low-gain afferents have regular spacing of interspike intervals. High-gain and acceleration afferents have a widely variable discharge regularity that is apparently unrelated to their rotational responses. Input/output transfer models were fit to the response data to describe the lowand high-pass filtering properties of the 3 afferent groups.
\end{abstract}

The function of the vestibular semicircular canals is to generate neural information in response to angular movement of the head. This information is encoded as changes in the firing rate of canal primary afferents. Horizontal canal afferents are stimulated when the force associated with angular acceleration deflects the cupula toward the utricle (Lowenstein and Sand, 1940; Goldberg and Fernandez, 1971; Precht et al., 1971; Blanks et al., 1975; Keller, 1976; Louie and Kimm, 1976; O'Leary et al., 1976); however, the magnitude of modulation and the phase relationship to head velocity of individual afferents show a wide variation to a given natural stimulus. The basis for this variation is not fully understood. The location of an afferent's dendritic processes in the sensory epithelium of the crista ampullaris (O'Leary and Honrubia, 1976; Honrubia et al., 1989) and the extent of individual dendritic arbors reflecting a variable number of innervating hair cells (Baird et al., 1988) might be factors. Further, the nonuniformity in the degree of displacement of

\footnotetext{
Received July 13, 1989; revised Nov. 27, 1989; accepted Dec. 1, 1989.

This work was supported by NIH NS 21055, and in part from an NIH Postdoctoral Fellowship (R.B.). We wish to thank Bertha McClure for histological assistance and Dr. Robert Peterka for help in the transfer functions.

Correspondence should be addressed to Dr. R. Boyle, Department of Otolaryngology, Oregon Health Sciences University, 3515 S.W. VA Hospital Road, Portland, OR 97201

Copyright (C) 1990 Society for Neuroscience $0270-6474 / 90 / 051557-13 \$ 02.00 / 0$
}

different portions of the cupula (Hillman, 1974; Hillman and McLaren, 1979; McLaren and Hillman, 1979) probably also influences responses. Many other morphological and physiological peripheral vestibular features could account for the observed differential responses of afferents. To cite a few examples, the tightness of coupling of the individual kinocilia to the cupula could vary over the 3-dimensional surface of the crista (Hillman, 1977), hair cells might have unmatched ratios of depolarizationtransmitter-secretion in different locations on the crista, hair cells might have unequal sized quanta of transmitter, afferents might have dissimilar postsynaptic sensitivities to a unit of transmitter released by a hair cell, or the synaptic cleft might vary in width, resulting in different diffusion times across it.

Common to other vertebrate species, the vestibular portion of the VIIIth nerve of the fish is composed of thin- to largediameter fibers (Ramón y Cajal, 1908). However, the sensory epithelium of the toadfish shows less morphological complexity than that of higher animals: only type II, but not type I, hair cells are present, and they and the supporting cells are restricted to the dorsalmost aspect of the crista ampullaris, with the slopes void of cells. This 2-dimensional hair cell array might result in a simpler movement profile of the cupula-ciliary complex in contrast to the 3-dimensional array and overlying cupular base and attachments in mammals. These anatomical diversities suggest that caution be applied in generalizing our results to other species.

The present experiment to characterize the horizontal canal nerve is the necessary first step in our analysis of the toadfish vestibular system. In a companion study the action of the efferent vestibular system on the afferents' discharge and rotational response is described (Boyle and Highstein, 1990), and preliminary reports of structure-function studies of the peripheral dendritic morphology and central termination patterns of primary afferents have been presented (Boyle and Highstein, 1986; Kitch and Highstein, 1987).

\section{Materials and Methods}

Preparation. Fifty adult toadfish, Opsanus tau, of either sex, weighing roughly $500 \mathrm{gm}$, provided useful data. Fish were supplied by the Marine Biological Laboratory where most of the experiments were done. Hearty specimens were selected for their aggressive behavior and housed in several hundred gallon aquaria with continuously running sea water. Fish were lightly anesthetized by immersion in MS222 (Finquel, Ayerst), partially immobilized by an intramuscular injection of pancuronium bromide $(0.05 \mathrm{mg} / \mathrm{kg})$, and secured in a plastic experimental tank. The tank was placed atop a rate table (Contraves-Inland Motors), equipped with a DC torque velocity-servomotor and electrical slip-rings. The head of the fish was pitched about $10^{\circ}$ nose-down to align the horizontal canal 
Figure 1. Examples of responses of 2 horizontal canal afferents to sinusoidal stimulation of ampullary receptors. Traces from top to bottom are: velocity profile of sinusoid $( \pm 25 \% \mathrm{sec})$, instantaneous firing rate of afferent (imp/sec), stimulus velocity averaged over consecutive cycles of rotation, and the corresponding cycle histogram of the averaged response. Solid line through each histogram is the afferent's DC firing rate, and dotted curve (present in $A$ but not readily visible) is the best sine fit to the response modulation. $A$, Low-gain afferent. $B$, High-gain afferent.
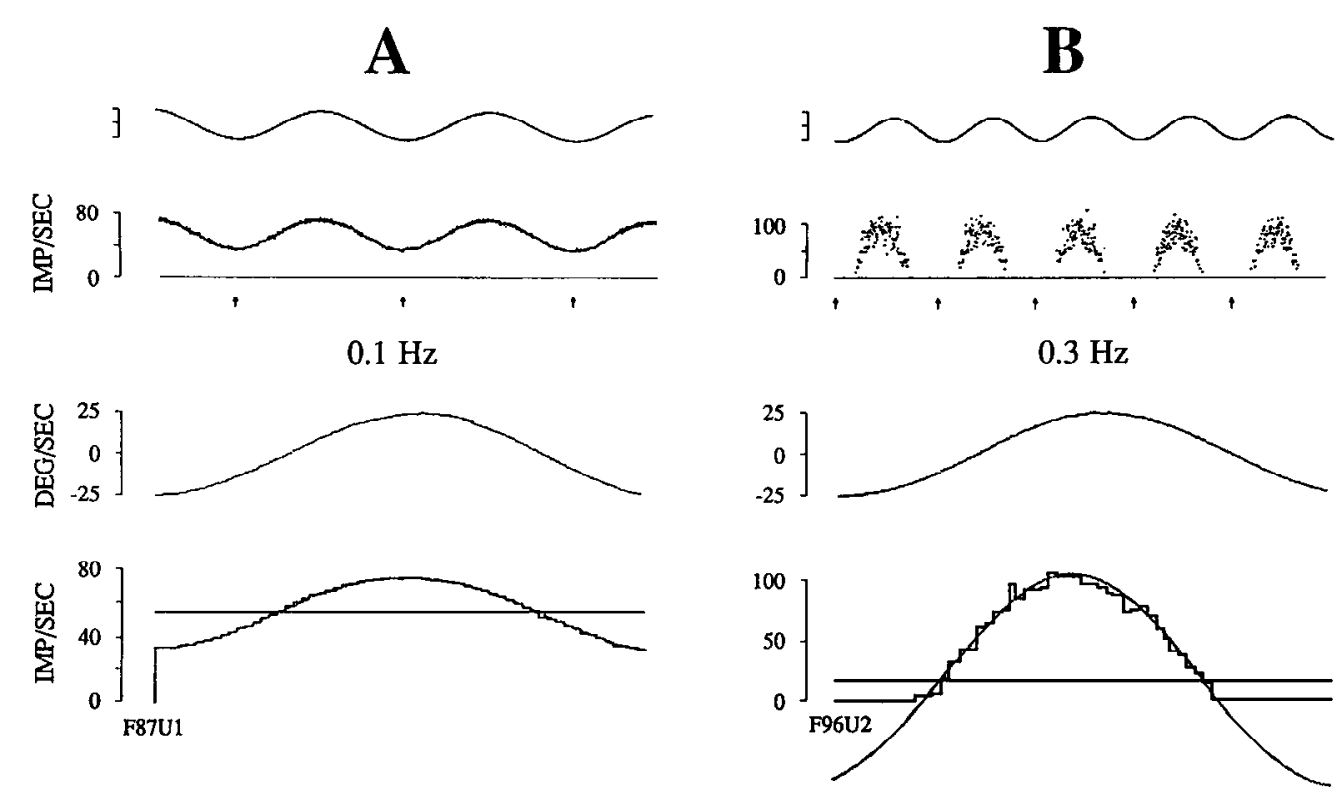

in the plane of table rotation and the center of rotation was adjusted to pass through the fish's intercanal axis. The fish was perfused continuously through the mouth with running sea water. The water level in the tank covered the fish's gills and $2 / 3$ of the body, and the eyes and remainder of the body were kept covered with moist tissues.

Skull markings identify the positions of the vertical semicircular canals. Using these marks, a small craniotomy, ca. $2-3 \mathrm{~mm}$ in diameter, was made lateral to the dorsal course of the anterior canal and rostral to the common crus, to expose the horizontal canal nerve where it is visible near the ampulla (the fish has no otic capsule); blood vessels often cover the nerve and were left intact. This surgical approach allows direct access to the horizontal canal nerve without disturbing the membranous labyrinthine structures. Within $1 \mathrm{~mm}$ of the ampulla the nerve often lies partially under the utricular sac but always rests on the roof of the sacculus, which serves as a support and provides stability for long-term unit recording. It was at this site that $\mathrm{NaCl}$-filled glass microelectrodes (10-20 $\mathrm{M} \Omega$ ) were inserted into the nerve using a micromanipulator under visual control. The cerebrospinal fluid space was filled with a fluorocarbon (FC80, 3M Corp.).

Extracellular unit potentials were conventionally amplified, displayed, and converted to standard pulses. Unit and stimulus data were fed directly into a computer (DEC PDP11/73) for storage and later analysis. The idealized spikes and a stimulus cycle trigger were sampled by 10 $\mathrm{kHz}$ clock interrupts. The analog signals of angular table position (from a rotary potentiometer) and velocity (from a tachometer) were digitally sampled at the conversion rate of $50-400 \mathrm{~Hz}$.

Rotational stimuli. Sinusoids and constant velocity trapezoids were delivered by an external function generator (Wavetek Model 146; computed signal distortion $<0.03 \%$ ). Routine tests to characterize the afferent's response to sinusoidal rotation consisted of stimuli applied between 0.01 and $1.0 \mathrm{~Hz}$ at 10 and $25 \% \mathrm{sec}$. Where possible, additional tests examined the afferent's frequency response across an extended frequency range of $0.001-10.0 \mathrm{~Hz}$ and at amplitudes of $5-100 \% / \mathrm{sec}$; mechanical restrictions limited rotations of $100,50,25$, and $10^{\circ} / \mathrm{sec}$ to $0.5,1.0,2.0$, and $5.0 \mathrm{Izz}$, respectively, and above $5 \mathrm{IIz}$ a $5 \% \mathrm{sec}$ stimulus was applied. The number of rotation cycles was matched in most instances to the frequency of oscillation to maintain an equal duration of angular stimulation for each experimental condition.

For ramp stimuli the table accelerated at $12 \% \mathrm{sec}^{2}$ to a constant velocity of $60 \% \mathrm{sec}$ for $>90 \mathrm{sec}$ and decelerated at $12 \% \mathrm{sec}^{2}$ to a stop. Afferents were first typed based on their response to a short series of sinusoids form 0.1 to $1.0 \mathrm{~Hz}( \pm 10 \% \mathrm{sec})$. Response adaptation to prolonged periods of constant acceleration was not examined.

Data analysis. Spike train data from 30 to 120 -sec periods of unstimulated, background discharge were recorded and stored for off-line analysis. The degree of discharge regularity or coefficient of variation (CV), defined as the standard deviation of the interval divided by the mean interspike interval, was computed from 100 to 4000 intervals. Calcu- lations were made on blocks of 10-20 sec taken at random and on the entire spike train. Samples of background activity were collected throughout the session to check the stability of the recording conditions.

An off-line computer analysis routine displayed the afferent's response to individual sinusoids to allow isolation and removal of contaminated records before data averaging. Averaged cycle histograms were then constructed using 256 bins to evaluate the response. I Iowever, to limit the loss of time resolution and discontinuity using finite-width binned data which may occur particularly for long cycle times, the bins were partitioned and the contribution of each spike to a given bin was linearly interpolated proportional to the distance from the spike to the bin center. The maximum and averaged number of spikes were calculated to provide a measure of the peak rate and the average rate in $\mathrm{imp} / \mathrm{sec}$ over the stimulus cycle, respectively. The magnitude and phase shift of the fundamental spectral component of the response were computed and fit by sine wave using the least mean-squared error procedure. Parameters calculated to describe the response modulation were: a d-c component of $D C$ firing rate about which the response was modulated, defined as the rate in imp/sec at one-half the peak-to-peak amplitude, the sensitivity defined as one-half the amplitude over one-half the peakto-peak stimulus velocity in imp/sec per $\% / \mathrm{sec}$, the phase expressed as the difference in arc degrees between the peak amplitude and the peak stimulus velocity, and the percent time of discharge or percent conduction occurring over the cycle time. In afferents that maintained a discharge over the entire stimulus cycle ( $100 \%$ conduction) the average rate and the DC firing rate were nearly identical and equivalent to the afferent's background (unstimulated) discharge, indicating a symmetrical response modulation (peak excitatory and inhibitory response of equal amplitude) centered about a steady firing rate. When the rate was "clipped" or silenced during a portion of the rotational cycle (percent conduction $<100 \%$ ), the response was assumed periodic and the DC firing rate and magnitude of the fundamental component were estimated by a Fourier series expansion, and a sine wave was fit to the nonzero or conducting portion of the response. The DC firing rate in these instances may significantly differ from the average rate over the stimulus cycle calculated form the raw data, even to the extent of assuming a negative value; this was most evident in afferents that discharge over less than one-half the stimulus cycle and have a large excitatory rotational response. A correlation coefficient was calculated between the spike data and the fitted waveform over the stimulus cycle taking into account bins without events, and the percent distortion was measured in some afferents as the ratio of the rms amplitude of the 2nd to 10th harmonics to that of the fundamental component of the rate function. Averaged data are expressed as mean $\pm \mathrm{SD}$.

Figure 1 presents the response patterns commonly found and the form of the data analysis. The top panel of each record is the afferent's instantaneous firing rate (lower trace) over several continuous rotation cycles of $\pm 25 \%$ sec (upper trace), and the bottom panel is the averaged 

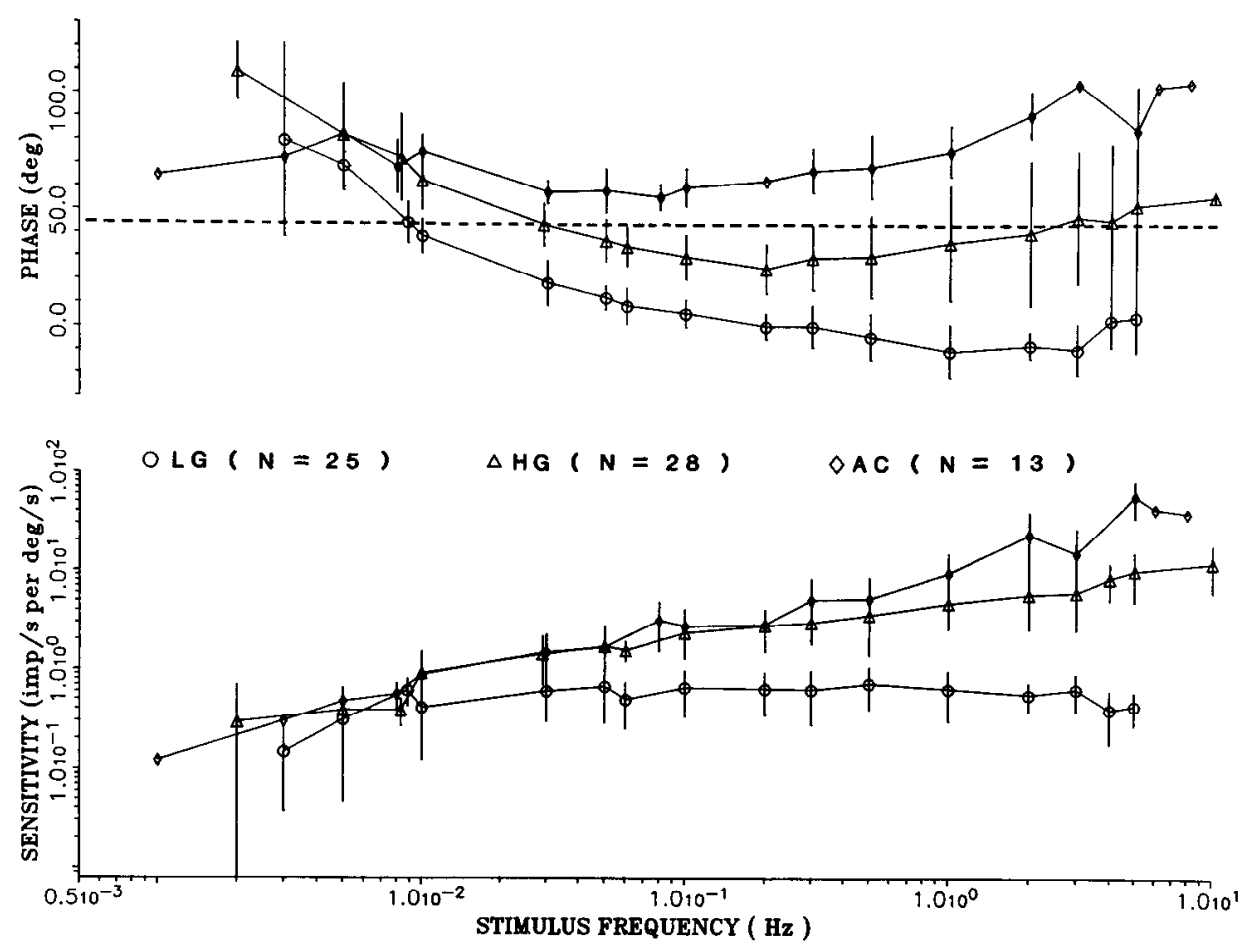

Figure 2. Bode plots of the averaged $( \pm \mathrm{SD})$ responses of 25 low- gain (circles), 28 high-gain (triangles), and 13 acceleration (diamonds) afferents to sinusoidal stimuli between 0.001 and 10.0 $\mathrm{Hz}$. Phase $\left(^{\circ}\right)$ is expressed with respect to peak $\left(0^{\circ}\right)$ stimulus velocity; positive values correspond to a phase lead and negative values a phase lag. A dashed line is drawn through the midpoint $\left(45^{\circ}\right)$ between peak stimulus acceleration and vclocity. Sensitivity is in imp/sec per $\%$ sec. The 3 subgroups are distinguished by their differing phase and sensitivity relations across the tested frequency bandwidth.

response over $5(A)$ and $15(B)$ cycles. The dotted curve through each histogram is the best sine fit to the estimated response, and the solid line is the DC firing rate. The afferent's response in Figure $1 A(0.1 \mathrm{~Hz})$ is characterized by an average and DC firing rate of $53.9 \mathrm{imp} / \mathrm{sec}$, a sensitivity of $0.86 \mathrm{imp} / \mathrm{sec} \mathrm{per} \% \mathrm{sec}$, and a phase lead of $7.5^{\circ}$; this afferent had a regular discharge pattern at rest $(\mathrm{CV}=0.05$; background rate $=$ $51.2 \mathrm{imp} / \mathrm{sec}$ ). Figure $1 B$ illustrates an example in which an afferent's firing rate occurs over only $56 \%$ (percent conduction) of the $0.3-\mathrm{Hz}$ stimulus cycle. This response is described by a sensitivity of $3.57 \mathrm{imp} /$ $\mathrm{sec}$ per $\% \mathrm{sec}$ and a phase lead of $28.8^{\circ}$. During the cycles the response centered about a lower DC firing rate $(16.2 \mathrm{imp} / \mathrm{sec})$ than the average rate $(39.1 \mathrm{imp} / \mathrm{sec})$. However the average and background discharge $(41.2 \mathrm{imp} / \mathrm{sec} ; \mathrm{CV}=0.52)$ were similar.

A nonlinear model fitting technique was used to describe the afferents' averaged responsc sensitivity and phase data over the examined frequency range of sinusoidal rotation (Seidel, 1975). After specifying the general form and number of parameters of the transfer function (e.g., Results, Transfer Models), the computer routine provided the initial estimates of the fit parameters based on minimizing the mean-squared error between the data and the fit model. Minor adjustments of one or more parameters were then made until the fit closely matched by eye both sets of data. The calculated values of the gain factor, $\mathrm{C}$, are not directly comparable across the different fit models.

\section{Results}

Sixty-six primary afferents were studied in sufficient detail to describe their response to sinusoidal rotational stimuli in the yaw plane. In 12 cases the responses to constant velocity trapezoids were also obtained.

\section{Afferent responses in the frequency domain: classification of afferents}

Construction of individual Bode plots for the 66 afferents showed that the afferents vary in their responses to sinusoidal rotations, and these variations provided a means for classifying the afferents into descriptive groups. Figure 2 shows the Bode plots of the avcragcd phase (upper curves) and sensitivity (lower curves) of response re:stimulus velocity for the 3 groups. One group of afferents was labeled acceleration sensitive (AC, diamonds; $n=$
13 , or $20 \%$ ) because the phase of response leads stimulus velocity $>45^{\circ}$ at all frequencies and amplitudes examined; a progressive and pronounced frequency-dependent sensitivity increase and phase advance was also observed. Of the remaining and larger sample of afferents showing a phase lead re:velocity $<45^{\circ}$ at one or more stimulus frequencies, 2 groups were recognized by their dissimilarity in sensitivity over the higher frequencies of rotation $(\geq 1 \mathrm{~Hz})$. High-gain afferents $(\mathrm{HG}$, triangles; $n=28$, or $42 \%$; example Fig. $1 B$ ) exhibit a high-frequency sensitivity increasc, while low-gain afferents (LG, circles; $n-$ 25 , or $38 \%$; example Fig. $1 A$ ) sustain a nearly flat sensitivity curve independent of stimulus frequency. For example, the averaged sensitivities (imp/sec per $\% \mathrm{sec}$ ) at 0.01 and $1.0 \mathrm{~Hz}$ are $0.42 \pm 0.29$ and $0.58 \pm 0.35$ for low-gain afferents and $0.93 \pm$ 0.62 and $4.92 \pm 2.28$ for high-gain afferents, respectively. The phase differences observed between low- and high-gain afferents can be summarized as follows. The averaged corner of the lowfrequency response (i.e., the frequency at which the response leads stimulus velocity by $<45^{\circ}$ ) for low-gain afferents was 0.009 $\pm 0.003 \mathrm{~Hz}$ (range $0.005-0.017 \mathrm{~Hz}$ ) and that for high-gain afferents was $0.032 \pm 0.013 \mathrm{~Hz}$ (range $0.019-0.06 \mathrm{~Hz}$ ). Above $0.05 \mathrm{~Hz}$ the phase of low-gain afferents leads or lags peak velocity $<10^{\circ}$, while that of high-gain afferents reaches a minimum lead of $25.7 \pm 10.7^{\circ}$ at $0.2 \mathrm{~Hz}$ and thereafter shows a progressive advance, extending on the average to $>45^{\circ}$ at frequencies above $3.0 \mathrm{~Hz}$. For descriptive purposcs we will refer to the afferents throughout as low-gain, high-gain, and acceleration afferents, although evidently they represent a broad spectrum and not distinct classes.

\section{Background discharge}

The mean background rate was $49.1 \pm 34.5 \mathrm{imp} / \mathrm{sec}$, ranging from 0.7 to $134.0 \mathrm{imp} / \mathrm{sec}(n=66)$. The CVs also covered a broad range, from 0.04 for the most regularly discharging afferent to 1.1 for an afferent having very irregular interspike 


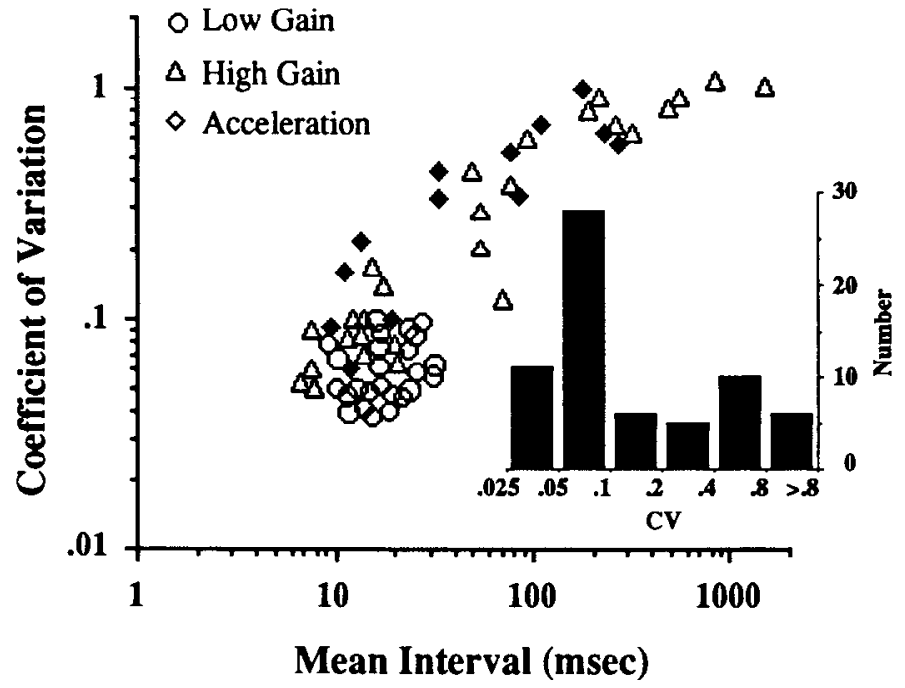

Figure 3. Relation between the mean interspike interval (in $\mathrm{msec}$ ) and the coefficient of variation ( $\mathrm{CV}$ ) of background discharge of 66 afferents. Symbols represent 3 subgroups distinguished by their rotational responses: low-gain (circles, $n=25$ ), high-gain (triangles, $n=28$ ), and acceleration (diamonds, $n=13$ ) afferents. Inset, Distribution of CVs of afferents in main graph $(n=66)$.

intervals, and averaged $0.26 \pm 0.30$. Figure 3 plots the $\mathrm{CV}$ and mean interspike interval of the background discharge for the 66 afferents, and the histogram (inset) shows the distribution of CVs. On the 2 ends of the mean interval spectrum afferents having rates $>100 \mathrm{imp} / \mathrm{sec}$ had regular intervals (low CVs) and those having rates $<10 \mathrm{imp} / \mathrm{sec}$ had irregular intervals (high CVs). However, most afferents (39/66 or $59 \%$ ) had regular interspike intervals with a $\mathrm{CV} \leq 0.1$, and no correlation was observed between resting rate and $\mathrm{CV}$.

\section{Relation of $\mathrm{CV}$ to rotational responses}

The background discharge characteristics in Figure 3 are keyed to the descriptive groups of Figure 2. Low-gain afferents (circles) had regular interspike intervals (CVs ranging form 0.04 to 0.10 , mean $0.06 \pm 0.02$ ) and a mean rate of $61.3 \pm 18.9 \mathrm{imp} / \mathrm{sec}$. However, regular spacing of the interspike intervals was not a feature unique to this group. High-gain afferents (triangles) had the widest range of CVs $(0.05-1.10$; mean $0.37 \pm 0.35)$ and rates $(0.7-134 \mathrm{imp} / \mathrm{sec}$; mean $43.2 \pm 42.3 \mathrm{imp} / \mathrm{sec})$. Eleven of the 28 high-gain afferents (39\%) had an averaged CV of $0.08 \pm$ 0.02 and a mean rate of $85.6 \pm 31.6 \mathrm{imp} / \mathrm{sec}$ and thus have background discharge characteristics comparable to that of lowgain afferents. The acceleration afferents (filled diamonds) also had a wide range of CVs $(0.06-1.00$; mean $0.40 \pm 0.28)$ and rates $(3.7-92.2 \mathrm{imp} / \mathrm{sec}$; mean $38.0 \pm 34.6 \mathrm{imp} / \mathrm{sec})$. Three acceleration afferents $(23 \%)$ had regular interspike intervals (CV $\leq 0.1)$ and rates ranging from 51.9 to $92.2 \mathrm{imp} / \mathrm{sec}$. Therefore, regularly discharging afferents can show widely disparate responses to rotational stimuli.

Certain response properties of mammalian vestibular nerve afferents can be correlated with their regularity of discharge (Fernandez and Goldberg, 1971; Goldberg et al., 1984; Baird et al., 1988). Figure 4 plots the afferents' phase (upper graph) and sensitivity (lower graph) versus their corresponding CVs; data were collected at a single midfrequency test of $0.3 \mathrm{~Hz}, \pm 25^{\circ}$ sec (darkened symbols are responses of afferents tested at 0.3 $\mathrm{Hz}$ but at a reduced amplitude of 5 or $10 \% \mathrm{sec}$ because response

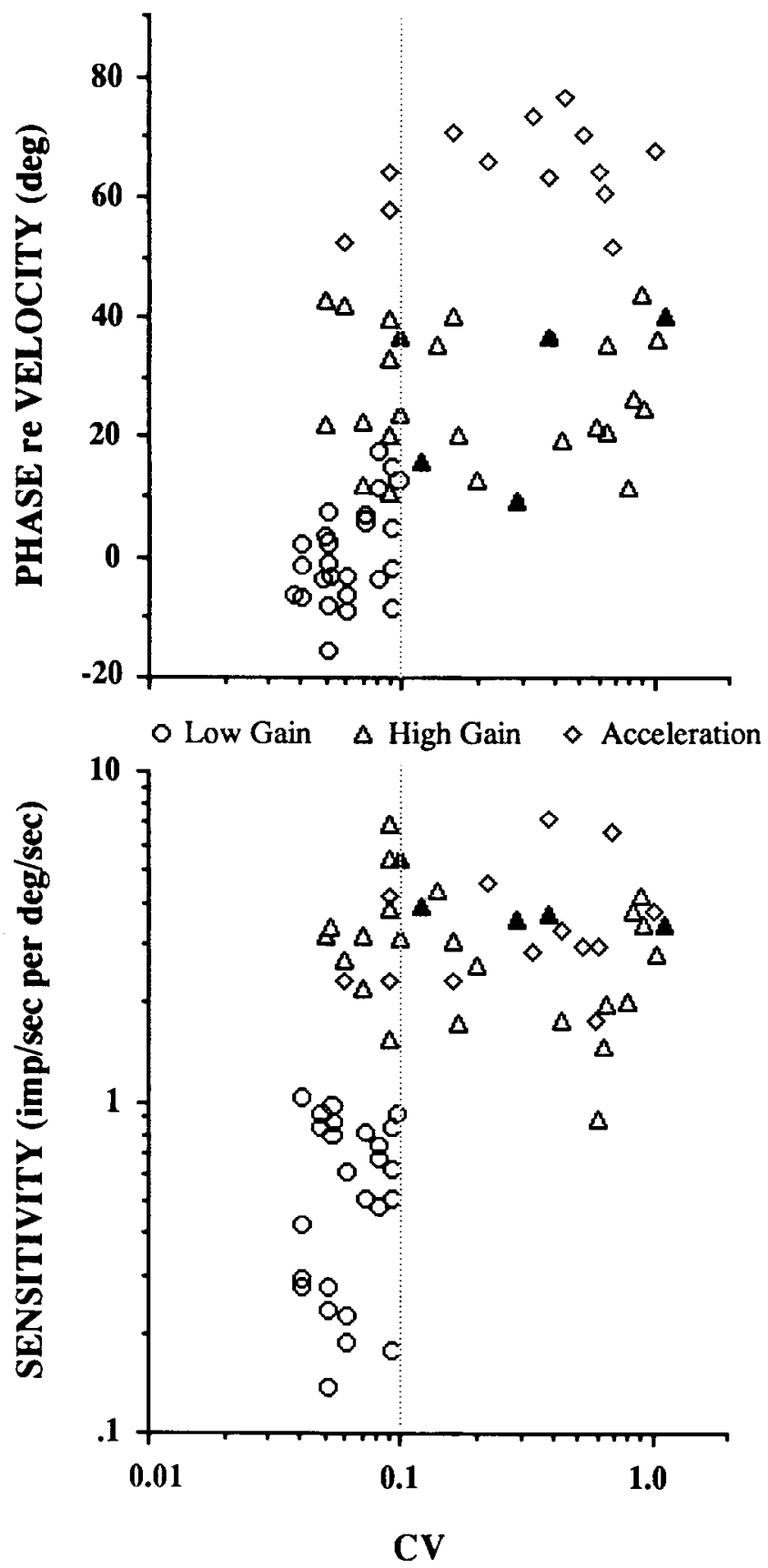

Figure 4. Phase (upper) and sensitivity (lower) of response at $0.3 \mathrm{~Hz}$ of 66 afferents are unrelated to the $\mathrm{CV}$ of their background discharges; same symbols as Figure 3.

distortion was detected at the $25 \%$ sec stimulus; response nonlinearities will be described later). A vertical dotted line is drawn at a CV of 0.1 in each plot. Regularly discharging afferents $(\mathrm{CV}$ $\leq 0.1$ ) showed the widest disparity of phase $\left(-16.4\right.$ to $\left.63.9^{\circ}\right)$ and sensitivity $(0.16-6.9 \mathrm{imp} / \mathrm{sec}$ per $\% \mathrm{sec})$ of response. For afferents having similar rotational responses the CV could vary over an order of magnitude. Therefore, the response sensitivity and phase of toadfish afferents to rotation cannot be inferred a priori from their regularity of resting discharge.

High-gain afferents showed the widest variation in background discharge characteristics (see Fig. 3, triangles) and response sensitivity and phase (see SD bars in Fig. 2, triangles). 

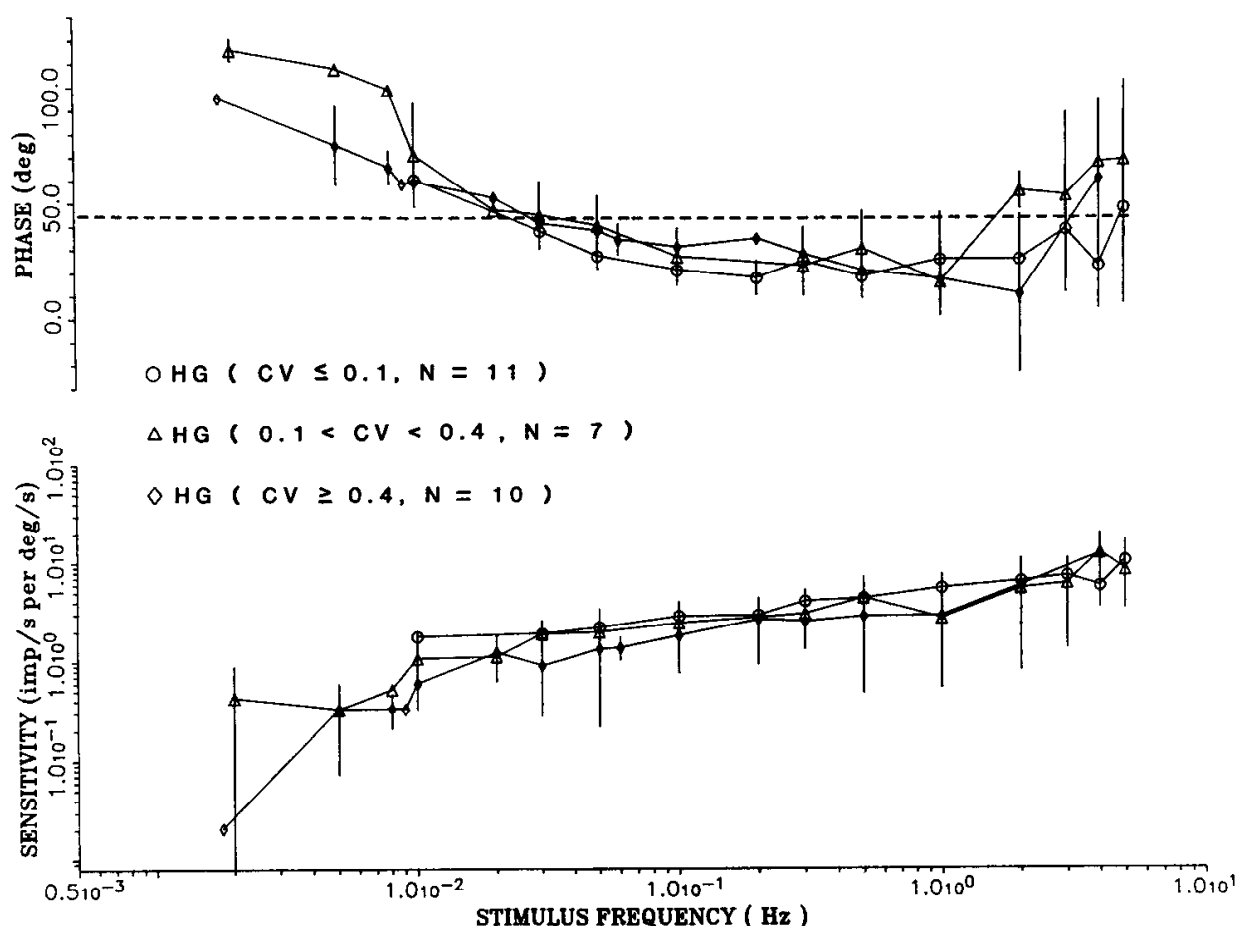

Figure 5. Bode plots of the averaged $( \pm \mathrm{SD})$ responses of high-gain afferents divided into 3 subpopulations based on their regularity of background discharge and represented by different symbols as indicated. Note the superposition of phase and sensitivity curves, suggesting an independence of the response dynamics on the regularity of background discharge.
Therefore, the correlation between $\mathrm{CV}$ and response dynamics was examined in this population. Figure 5 shows the Bode plots of 3 subpopulations of high-gain afferents divided by their CVs into regular $(\mathrm{CV} \leq 0.1 ; n=11)$, intermediate $(0.1<\mathrm{CV}<0.4$; $n=7)$, and irregular ( $\mathrm{CV} \geq 0.4 ; n=10)$. The response curves overlap for the subpopulations. Thus no direct relationship between the regularity of background discharge and the response dynamics to rotation could be extrapolated.

\section{Transfer models}

Figure 6 replots the averaged sensitivity (open symbols) and phase (filled symbols) for the 66 afferents. Curves through each data set are the indicated input-output transfer model of stimulus frequency and response modulation.

Low-gain afferents are presented in Figure $6 A$ (circles). The data were fit by a transfer function in the form of a first-order torsion pendulum model, $H(s)=C s /\left(\tau_{1} s+1\right)$. $C$ is a gain factor and $\tau_{1}$, the long time constant governing the response over lower frequencies, is $18.1 \mathrm{sec}$. No deviation of averaged behavior of these afferents was observed up to $5 \mathrm{~Hz}$; above $5 \mathrm{~Hz}$ the $\pm 5^{\circ}$ / sec stimulus was insufficient to modulate low-gain afferents.

Figure $6, B$ and $C$, shows 2 transfer functions fit to the averaged high-gain afferents' response. In Figure $6 B$ the data were fit to a model proposed by Fernandez and Goldberg (1971) for the squirrel monkey canal afferents and is expressed in the form $H(s)=C s^{2}\left(\tau_{v} s+1\right) /\left[\left(\tau_{a} s+1\right)\left(\tau_{1} s+1\right)\left(\tau_{2} s+1\right)\right] . C$ is the gain factor; $\tau_{1}$, the long time constant, is $5 \mathrm{sec} ; \tau_{\mathrm{v}}$, the time constant of the velocity sensitive lead operator, is $0.096 \mathrm{sec}$; and the theoretical estimate of the short time constant $\tau_{2}$ is $0.006 \mathrm{sec}$. Time constant of the low-frequency adaptation operator, $\tau_{\mathrm{a}}$, is $280 \mathrm{sec}$, and, although it expresses a negligible influence of adaptation at the frequencies tested, it provides for the observed phase lead $>90^{\circ}$ (re:velocity) at $0.002 \mathrm{~Hz}$.

Figure $6 C$ presents a second model fit of the high-gain afferents' response. The transfer function uses a scaled fractional zero term, $(s+\text { constant })^{\mathrm{k}}$, to describe the continuous high-pass filtering, and is expressed in the form $H(s)=C s^{2}(s+b)^{\mathrm{k}} /\left[\left(\tau_{\mathrm{a}} s\right.\right.$ $\left.+1)\left(\tau_{1} s+1\right)\right]$. $C$ is the gain factor, the long time constant $\tau_{1}$ is $5 \mathrm{sec}$, the adaptation time constant $\tau_{\mathrm{a}}$ is $253.8 \mathrm{sec}$, and the fractional exponent is 0.54 . The time constant $\left(\tau_{2}\right)$ of the second pole in the transfer function of $B$ was excluded. Over the examined range of frequencies, the transfer function closely approximates the data.

Figure $6 D$ fits 2 models to the averaged data of the 13 acceleration afferents. The first transfer function (solid line) is in the form of an accelerometer, $H(s)=C s$, where $C$ is the gain factor, and only roughly estimates the data (44\% error fit). To account for the apparent velocity sensitivity, i.e., the phase lag re: acceleration and the flattening of the sensitivity curve, over the middle stimulus frequencies, the dala were fit by the transfer function (dotted curve), $H(s)=C s\left(\tau_{\mathrm{v}} s+1\right) /\left(\tau_{1} s+1\right) . C$ is the gain factor, the long time constant $\tau_{1}$ is $5 \mathrm{sec}$, and the time constant of the velocity sensitive lead operator $\tau_{\mathrm{v}}$ is $1.25 \mathrm{sec}$. The large value of $\tau_{\mathrm{v}}$ limits the influence of the low-pass filtering provided by $\tau_{1}$ and prevents a phase lag re: acceleration $>45^{\circ}$. As described below, at higher frequencies of rotation additional terms, such as a saturation factor, are needed.

\section{Response to sinusoids in the stimulus amplitude domain}

To determine whether the responses of low- and high-gain afferents behave linearly to stimulus velocity, i.e., if the intensity functions superpose, responses were recorded at stimulus amplitudes of $5-50 \%$ sec at fixed frequencies of $0.01-1.0 \mathrm{~Hz}$ (peak accelerations of $0.3-157 \% / \mathrm{sec}^{2}$ ). Figure 7 is the averaged responses of the low gain $(A)$ and high-gain $(B)$ afferents. In Figure $7 A$ the response phase of low-gain afferents (upper graph) is dependent on stimulus frequency. At frequencies $<0.03 \mathrm{~Hz}$ (i.e., well above the corner frequency) the sensitivity is similar for a 10 -fold variation in amplitude (lower graph), suggesting a close proportionality of sensitivity to the velocity amplitude. A bi- 


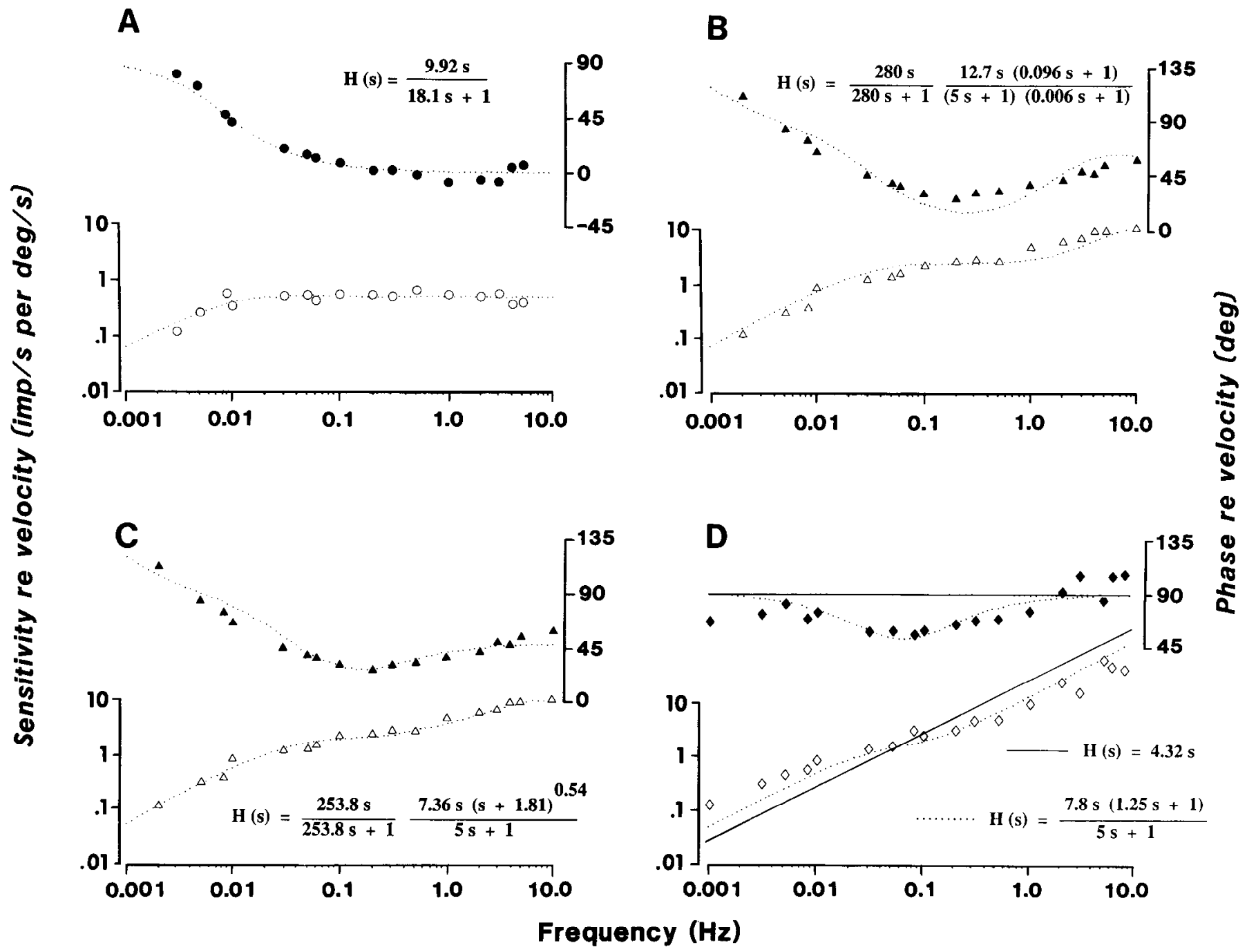

Figure 6. Transfer functions of afferents to sinusoids. Data are replotted from Figure 2 (SD bars omitted). Open and filled symbols are averaged sensitivity and phase of response, respectively. $A$, Low-gain afferents. $B$ and $C$, High-gain afferents. $D$, Acceleration afferents. Dotted curve or solid line through each data set is the indicated transfer model.

directional response over the stimulus cycle was present at all frequency and amplitude tests for 20 of the 25 afferents; in the 5 exceptions, the discharge was silenced on the average of $25 \%$ of the stimulus cycle at frequencies $(>0.1 \mathrm{~Hz}$ and $>25 \% \mathrm{sec}$. Other nonlinearities in the frequency and intensity responses (e.g., saturation, asymmetry) were not observed in these afferents.

Figure 8 is a Bode plot of the response of a single low-gain afferent to rotation from $0.009-3.0 \mathrm{~Hz}$ at amplitudes of $5-50 \%$ $\mathrm{sec}$ (peak acceleration of $0.3-95 \% \mathrm{sec}^{2}$ ). The superposition of the sensitivity curves suggests the response linearity of this afferent and is seen as the proportionate increase in the peak rate of discharge modulation for increases in stimulus amplitude (middle curves). This is an absolute increase in the depth of modulation because the DC firing term did not vary $(65.0 \pm 1.8$ $\mathrm{imp} / \mathrm{sec}, \mathrm{SD})$ for the 24 rotation tests. The background discharge of this afferent was also $65.0 \mathrm{imp} / \mathrm{sec}(\mathrm{CV}=0.07)$.

The averaged data of high-gain afferents are presented in Figure $7 B$. The upper curves show that the phase of response was frequency-dependent. The lack of superposition of sensitivities in the lower curves suggests a departure from response linearity in the stimulus amplitude domain. For rotations of equal amplitude a high-frequency-dependent sensitivity increase is evident. Further, the responses obtained at the 5 frequencies converge at the stimulus amplitude of $50 \% \mathrm{sec}$. The sensitivity of high-gain afferents thus appears to be a function of both frequency and velocity of the rotation, and a major nonlinear effect of stimulus amplitude may be characterized as response attenuation. A complete bidirectional response was present at all tested frequencies and amplitudes of rotation in only 7 of the 28 afferents; the remaining 21 afferents exhibited a "clipped" response modulation at one or more frequencies and amplitudes. The effect of response attenuation and distortion as a function of stimulus amplitude is examined more closely in Figures 9 and 10.

Figure 9 presents the data of one high-gain afferent in the form of a Bode plot from $0.003-10.0 \mathrm{~Hz}$ at amplitudes of 5$100 \%$ sec (peak accelerations of $0.09-314 \% / \mathrm{sec}^{2}$ ). Phase of response (upper traces) is again frequency-dependent. At each amplitude a high-frequency sensitivity increase is evident (lower traces). Note, however, that the sensitivity increase observed at each higher frequency for stimuli $>10 \% \mathrm{sec}$ is not proportionate 
A

\section{LOW GAIN AFFERENTS}
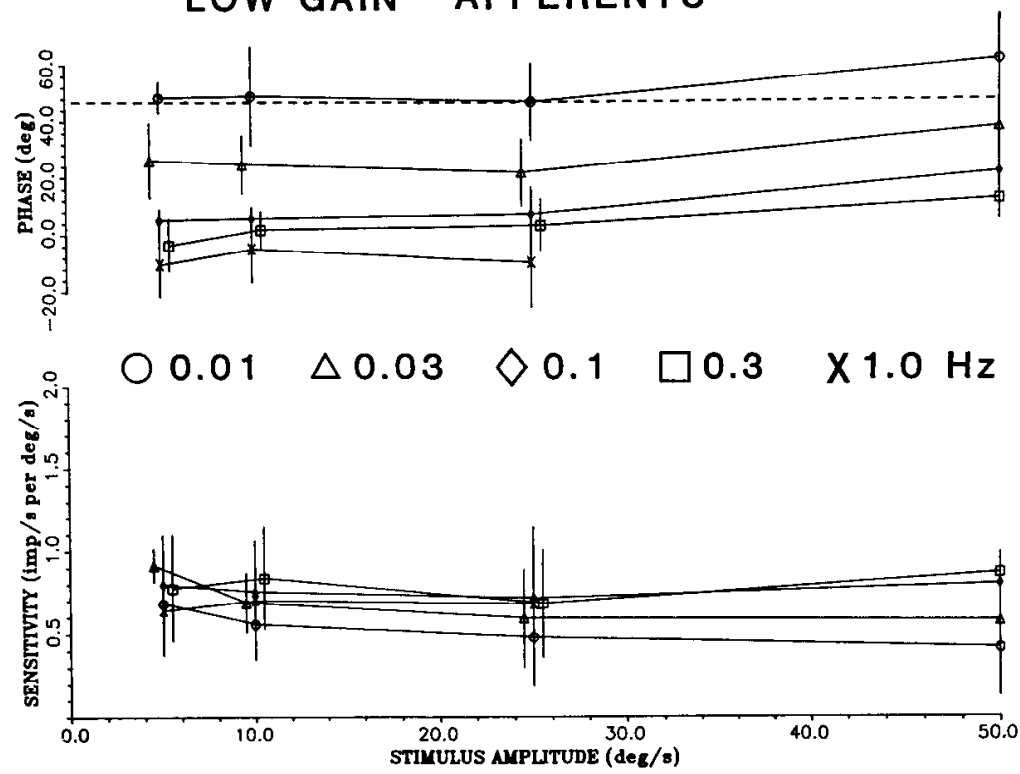

HIGH GAIN AFFERENTS

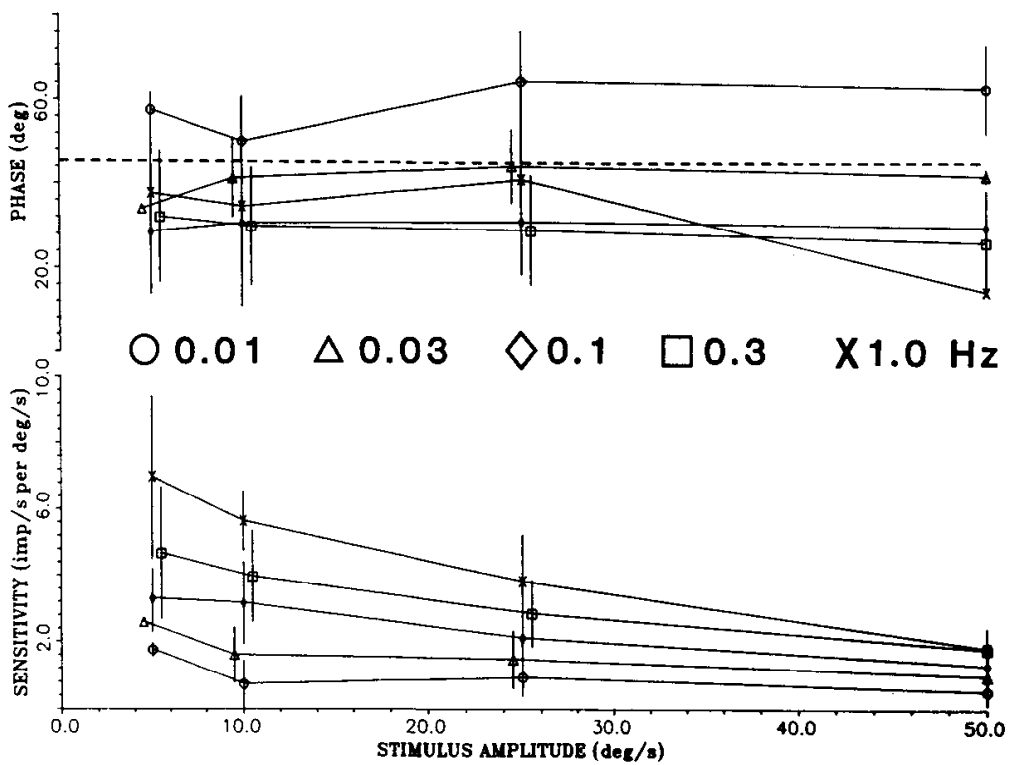

Figure 7. Responses of 25 low-gain $(A)$ and 28 high-gain $(B)$ afferents to variations in stimulus velocity from 5 to $50 \% / \mathrm{sec}$ at fixed frequencies of rotation from $0.01-1.0 \mathrm{~Hz}$ are represented by different symbols as indicated. Averaged phase and sensitivity (different scales) are plotted re: velocity. A dashed line is drawn at $45^{\circ}$ lead to peak stimulus velocity in each graph. to the increase in stimulus amplitude, and the curves do not superpose. The averaged DC firing rate varied little over the 35 tests $(19.0 \pm 2.2 \mathrm{imp} / \mathrm{sec}$; background rate $=18.7 \mathrm{imp} / \mathrm{sec}$ and $\mathrm{CV}=0.29$ ), and thus changes in the peak rate (middle curves) underlie this attentuation of the response sensitivity. The peak rate increased roughly proportionately for stimulus amplitudes from 5 to $10 \% \mathrm{sec}$. For stimuli of 25,50 , and $100 \% \mathrm{sec}$ the peak rates were similar at each frequency, thereby effecting the reduction in sensitivity. A static nonlinearity such as an upper rate limit cannot entirely account for this response reduction. Compare the peak rates of modulation for stimuli of $50 \% \mathrm{sec}$ (squares). A response reduction occurs already at $0.003 \mathrm{~Hz}$, at a point where the peak rate is less than one-half $(42.7 \mathrm{imp} / \mathrm{sec})$ that of the $1.0 \mathrm{~Hz}$ stimulus $(95.4 \mathrm{imp} / \mathrm{sec})$.

Nonlinearities of response of the same afferent presented in Figure 9 are illustrated by cycle histograms collected at $0.01 \mathrm{~Hz}$ for amplitudes of $5-100 \% \mathrm{sec}$ in Figure 10 . At the stimulus of $5 \% \mathrm{sec}$ the firing rate is sinusoidally modulated and reaches a peak rate of $28.6 \mathrm{imp} / \mathrm{sec}$, corresponding to a sensitivity of 1.8 $\mathrm{imp} / \mathrm{sec}$ per $\% \mathrm{sec}$. The sensitivity fell to $1.6,1.2$, and 0.76 , and $0.44 \mathrm{imp} / \mathrm{sec}$ per $\% \mathrm{sec}$ at stimuli of $10,25,50$, and $100 \% \mathrm{sec}$, respectively. For each increase in amplitude above $5 \%$ sec the 
Figure 8. Response of a single lowgain afferent to sinusoids. The phase $\left(^{\circ}\right)$, peak rate (imp/sec), and sensitivity (imp $/ \mathrm{sec}$ per $\% \mathrm{sec}$ ) of response are plotted for rotations from $0.01-3.0 \mathrm{~Hz}$ at four $(5-50 \% / \mathrm{sec})$ amplitudes (indicated by symbols). A dashed line is drawn at $45^{\circ}$. Note the proportionate increase in the peak rate of response for increases in stimulus velocity amplitude (middle graph) and thus the superposition of the sensitivity curves (lower graph).
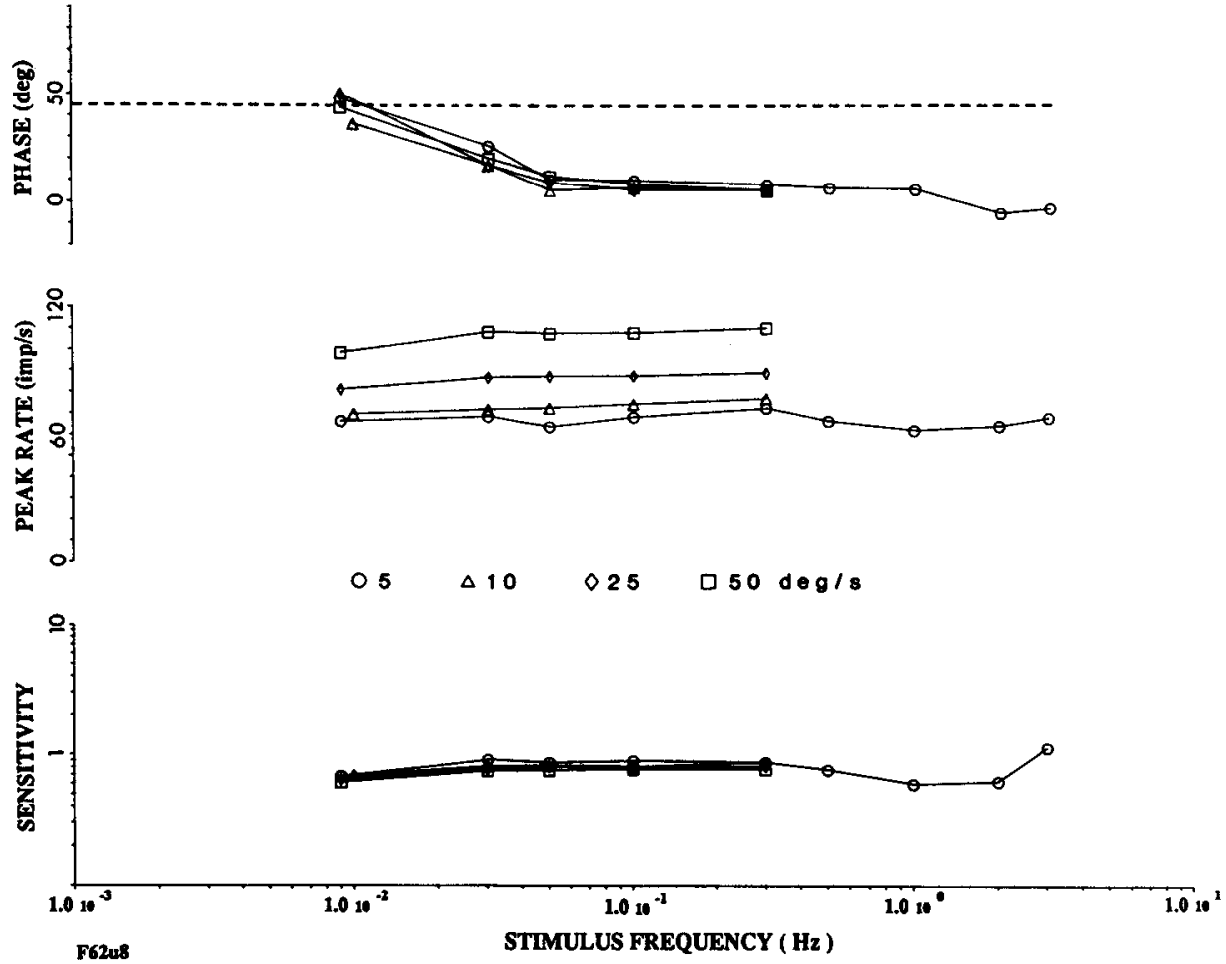

percent harmonic distortion of response nearly doubles, reaching $>60 \%$ at the $100 \% \mathrm{sec}$ stimulus. Consider the rising phase of the response, which is poorly fit by the dotted sine wave. A tangent to the excitatory rise of response would reveal a nearly proportionate increase in the firing rate for increases in stimulus amplitude from 5 to $25 \%$ sec. However, the peak of the response at 10 and $25 \%$ sec reaches a rate well below that observed for the afferent using different rotation tests. Above $25 \%$ sec the excitatory rise of response continues to increase, but disproportionately less by about $70 \%$ than that of the lower-amplitude responses. This might be expected if an input amplitude-dependent saturation nonlinearity were present. Another prominent response distortion is present in the form of an asymmetric rise and fall of response. This is most striking for the stimulus
Figure 9. Response of a single highgain afferent to sinusoids at 5 amplitudes $(5-100 \% \mathrm{sec})$ from $0.003-10.0 \mathrm{~Hz}$. Same format as Figure 8. Note the highfrequency sensitivity increase at each amplitude and the saturation of the peak rate for amplitudes $>25 \% \mathrm{sec}$ (middle graph).
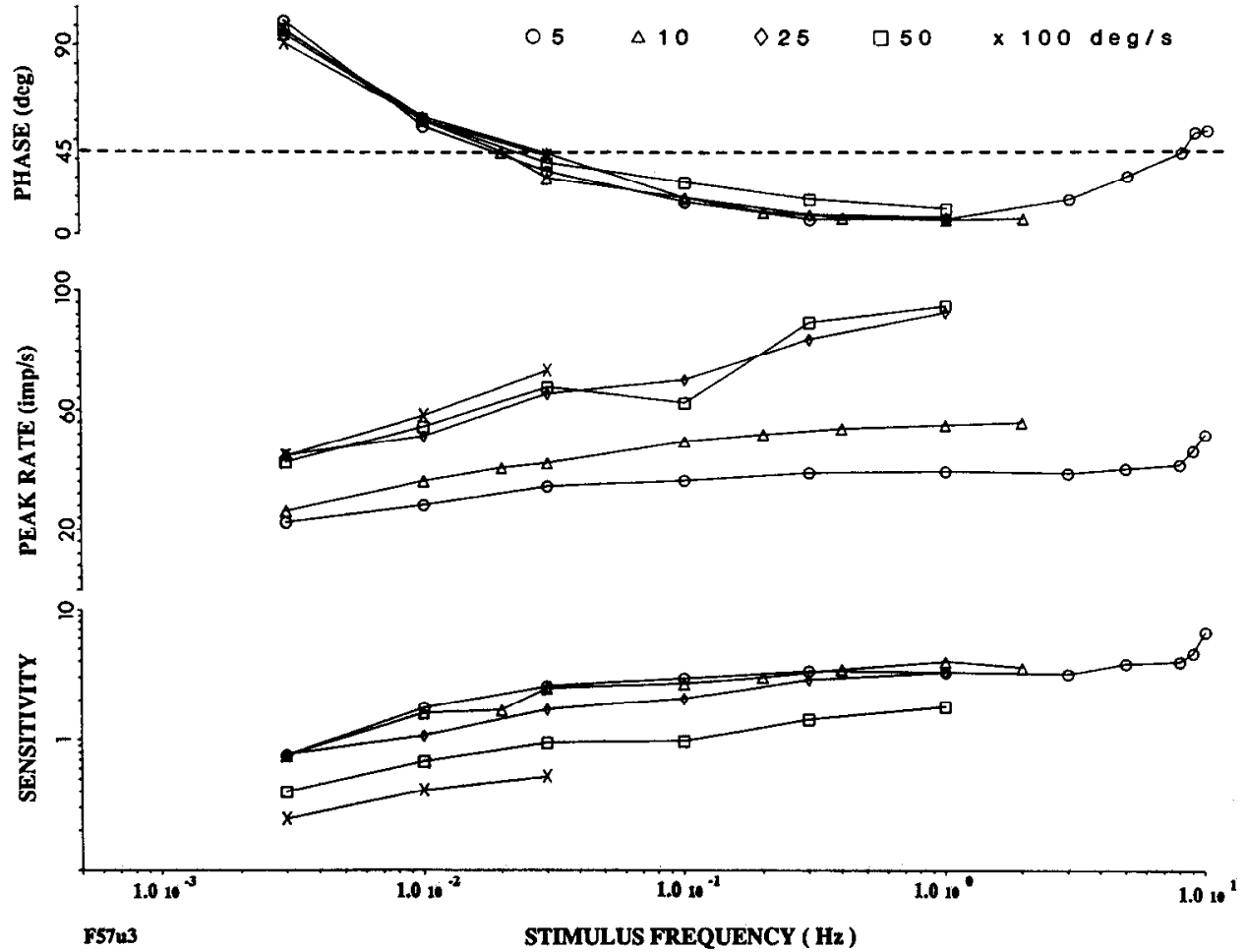
of $100 \%$ sec, where following an excitatory response up to 60 $\mathrm{imp} / \mathrm{sec}$ the rate progessively decreased. A static nonlinearity such as an input limit (e.g., maximum cupula displacement and hair cell excitement) cannot fully account for this discharge decline. At a fixed frequency of rotation an increase in stimulus velocity also increases stimulus acceleration. However, the frequency and acceleration of the stimulus were not responsible for the observed response saturation. The peak acceleration of the $25 \% \mathrm{sec}$ stimulus in Figure 10 is $0.63 \% \mathrm{sec}^{2}$. However, response nonlinearities were not observed for stimuli of $5 \% \mathrm{sec}$ across the frequency bandwidth (see Fig. 9, circles) even at 10.0 $\mathrm{Hz}$, where the peak acceleration is $314 \% \mathrm{sec}^{2}$. Of the $28 \mathrm{high}-$ gain afferents 8 showed nonlinearities exemplified by the afferent in Figures 9 and 10; for each the response distortion was stimulus amplitude-dependent and usually occurred at amplitudes $\geq 25 \%$ sec.

Two approximations of the response of acceleration afferents were described in Figure 6, one as that of an accelerometer and the other as that of a low-pass filter that was partially nulled by a powerful lead operator $\left(\tau_{v} s+1\right)$. To evaluate their response linearity to stimulus acceleration, data were compared for rotations of equal acceleration at different frequencies and plotted with respect to peak stimulus acceleration (Fig. 11). At all frequencies $(0.01-1.0 \mathrm{~Hz}$ ) and amplitudes of acceleration (range $\left.0.3-157 \% \mathrm{sec}^{2}\right)$ the phase of response was within $\pm 45^{\circ}$ of peak acceleration (upper graph, indicated by $0^{\circ}$ ). The superposition of the curves in the lower graph suggests an averaged response sensitivity re: acceleration independent of stimulus frequency. However, response sensitivity was not dependent entirely on the stimulus acceleration, as seen by the progressive fall in sensitivity of about $10 \mathrm{~dB} /$ decade of stimulus frequency, evident for amplitudes $>1.5-3.0 \% \mathrm{sec}^{2}$. A complete bidirectional response modulation at all frequencies and amplitudes of rotation was not observed in any acceleration afferent, and the modulation occurred over a progressively shorter period of the stimulus cycle, until at frequencies $>5 \mathrm{~Hz}$ the firing rate of these affcrents was silenced for about $50 \%$ of the stimulus cycle.

Nonlinearities of response were also observed for acceleration afferents. Only 2 acceleration afferents exhibited a sinusoidal modulation of the firing rate, without an attenuation of the peak rate and distortion of the response, for the tested rotations. The remaining 11 afferents showed response distortions qualitatively similar to those described for the 8 high-gain afferents. However, for the 11 acceleration afferents the response distortion occurred at stimulus frequencies $\geq 1 \mathrm{~Hz}$, independent of stimulus velocity or acceleration.

\section{Responses to constant velocity trapezoids}

Afferent responses to constant velocity profiles of $60 \% \mathrm{sec}$ were recorded in 12 cases. The afferents responded qualitatively in a similar fashion, with a rate increase in response to utriculopetal endolymph flow and a rate decrease in the opposite sense. Following the 5 -sec period of constant acceleration $\left(12 \% / \mathrm{sec}^{2}\right)$, the peak rate of the low- and high-gain afferents decayed exponentially toward the prerotational (background) level, as would be expected from the low-pass characteristics described in Figure 6. No secondary phenomena, such as an under- or overshoot of discharge following response recovery, were observed in this small sample of afferents. Of the 12 afferents, 4 were low gain, 7 high gain, and 1 was an acceleration afferent.

Figure 12 shows the velocity ramp responses of a low-gain $(A)$, high-gain $(B)$, and acceleration $(C)$ afferent. The excitatory

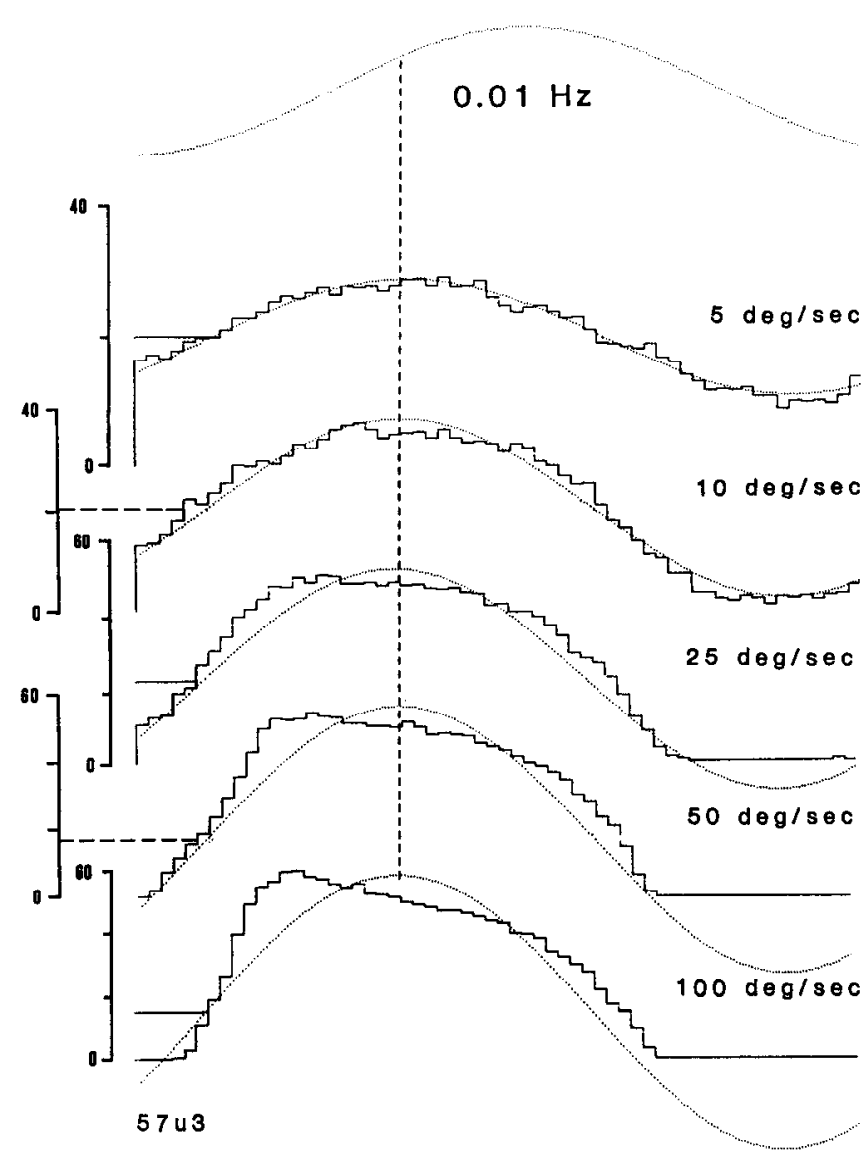

Figure 10. Response distortion of a high-gain afferent as a function of stimulus amplitude. Same afferent as in Figure 9. Five cycle histograms are presented for rotations of $0.01 \mathrm{~Hz}$ (uppermost trace) at 5-100\% $/ \mathrm{sec}$, indicated on the right-hand side of each histogram. The vertical dotted line represents a $60^{\circ}$ phase lead re: velocity; the horizontal line associated with each histogram specifies the DC firing rate (scale is in imp/sec). The dotted sine wave through each histogram is the estimated describing function and progressively misrepresents the response as the distortion increases for higher velocity amplitudes. Note the sharp rise in the firing rate which abruptly stops at about $60 \mathrm{imp} / \mathrm{sec}$ and declines for the $100 \%$ sec stimulus.

sensitivity of low-gain afferents averaged $0.33 \pm 0.02 \mathrm{imp} / \mathrm{sec}$ per $\% \mathrm{sec}^{2}$ (range $0.33-0.375$ ), and the mean peak rate following acceleration was $30.8 \pm 8.2 \%$ above background discharge. The time constant of response decline is $22.6 \mathrm{sec}$ for the afferent in $A$ and averaged $20.4 \pm 2.4 \mathrm{sec}$ (range of 17.0-22.6 sec) for the 4 low-gain afferents.

The afferent response in Figure $12 B$ represents that observed in high-gain afferents. The time constant of response decline following rotation in the on-direction ranged from 4.7 to 8.4 sec (afferent in $B$ ) and averaged $7.0 \pm 1.4 \mathrm{sec}$. The excitatory sensitivity of high-gain afferents to an acceleration step was twice $\left(0.77 \perp 0.30 \mathrm{imp} / \mathrm{sec}^{\mathrm{per}} \% \mathrm{sec}^{2}\right.$, range $\left.0.46-1.22\right)$ that observed for low-gain afferents. The average rate increase was about 9-fold above background discharge. In all cases the rate was completely silenced during or following deceleration.

The response of one acceleration afferent to an acceleration step is shown in Figure $12 \mathrm{C}$; the background rate was $5.4 \mathrm{imp}$ / sec and the peak rate of response was $91.2 \mathrm{imp} / \mathrm{sec}$, an approximate 17-fold increase above background discharge. Note the sharp drop in discharge toward the background rate after acceleration. 
Figure 11. Averaged response of 13 acceleration afferents to variations in stimulus acceleration at fixed frequencies of rotation from $0.01-1.0 \mathrm{~Hz}$ are represented by different symbols. Phase and sensitivity re: stimulus acceleration. $0^{\circ}$ is peak acceleration and a dotted line is drawn at $45^{\circ}$ lag.

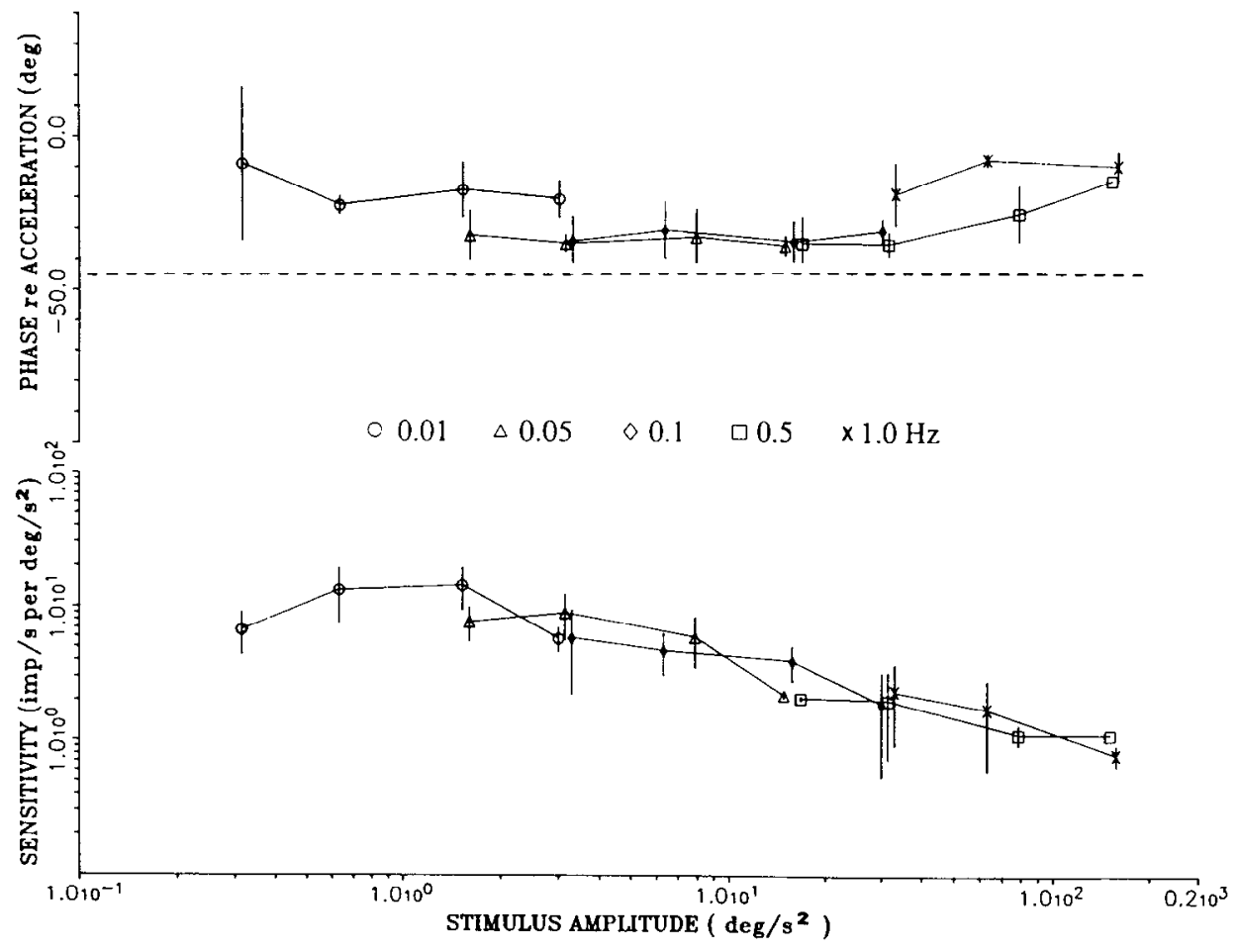

\section{Discussion}

In keeping with the findings of others, all horizontal canal afferents studied were excited by those rotations that deflected the cupula toward the utricle. The mean background rate for the 66 afferents studied was $49 \mathrm{imp} / \mathrm{sec}$. A high rate in primary afferents has the obvious advantage of allowing a bidirectional response to rotary stimuli. Fifty-nine percent of afferents had regular interspike intervals $(\mathrm{CV} \leq 0.1)$ and resting rates averaging 69 $\mathrm{imp} / \mathrm{sec}$ (range $32-134 \mathrm{imp} / \mathrm{sec}$ ). Regular afferents include the 25 low-gain afferents, which, therefore, comprise a large proportion $(64 \%)$ of those cells with higher resting rates.

In view of the findings of others (Goldberg and Fernandez, 1977; Yagi et al., 1977; Goldberg et al., 1984), it was surprising to find that the response sensitivity of toadfish afferents to sinusoids was not systematically related to their degree of discharge regularity. Regularity is presumably most affiliated with postspike voltage-dependent conductances that hyperpolarize the afferent membrane potential and then gradually allow a repolarization to threshold for impulse initiation (Hille, 1984). In a previous report about a mammalian labyrinth (Goldberg et al., 1984) a "causal link" was postulated between regularity and sensitivity as both are due, in part, to the postsynaptic properties of afferents. This view was amended (Baird et al., 1988) when a population of very irregular, lower-gain afferents was discovered in another mammal. In the bullfrog, the response gain of irregular afferents varied widely and was uncorrelated with discharge regularity (Honrubia et al., 1989). Our view is that sensitivity and regularity may be coincidentally, but not causally, related. This could be because the sensitivity of an afferent is determined at a different membranc sitc than the one containing the channels for the postspike conductances that confer regularity upon it. In the present data set it seems most probable that features presynaptic to afferents, such as cupular mechanics, the number of hair cells innervating a given afferent, the location of the subset of innervating hair cells, or the response dynamics of the hair cells themselves, may account for the differential sensitivity of afferents. These factors apparently do not co-vary with the determinants of regularity in this species. Thus it still seems reasonable to propose, based on available evidence, that the regularity of afferent discharge is primarily due to postsynaptic mechanisms as originally hypothesized (Highstein and Politoff, 1978), first modeled by Kernell (1968), and applied to the vestibular nerves by Goldberg et al. (1984). Unpublished intracellular records from regular and irregular afferents of the lizard (Schessel, 1982) seem to confirm this view.

The phase and symmetry of afferent response were also unrelated to the afferent's background discharge characteristics. Afferents having comparable resting rates and regularity of discharge differed widely in the degree of response symmetry for an applied head movement. The responses of low-gain afferents were largely symmetrical in the on- and off-directions of rotation at all stimulus frequencies and amplitudes examined. This suggests equivalent, bidirectional cupular mechanics and motion, and the closely linear responses in the stimulus amplitude domain presumably reflect the proportionate synaptic drive to these afferents for increases in the amplitude of movement in both directions at each frequency. In a previous communication (Boyle and Highstein, 1986) the dendritic locations of low-gain afferents intracellularly stained were confined to the peripheral portion of the hair cell epithelium, presumably where the cupula thickens (Hillman, 1974; Landolt et al., 1975) and its motion might be more mechanically restrained (tethered) by the wall of the ampulla. This might explain their low response sensitivity and the lack of response modulation at high-frequency rotations $( \pm 5 \% \mathrm{sec})$ where incrtial forces will have an increasing effect on cupular motion.

The more sensitive high-gain and acceleration afferents demonstrated pronounced response asymmetries, in the form of silencing of the discharge in the off-direction of rotation, at 
nearly all tests for fibers having low rates or for large-amplitude or high-frequency rotations for fibers having high rates, or a nonlinear distortion of the excitatory half-cycle of response, or both. This latter form of response distortion was stimulus-specific, being more amplitude-dependent for some high-gain afferents (Fig. 10) and frequency-dependent for most acceleration afferents. Segal and Outerbridge (1982) detailed the response nonlinearities, including response decline to prolonged rotational stimulation, in bullfrog canal afferents, and observed a similar response saturation and skewness (greater excitatory rise than fall of response) that is highly affected by the input magnitude. An upper rate limit cannot account for the response saturation in the examined afferents since the fiber's rate could be driven higher by using other stimuli (scc Fig. 9). Wc attribute the saturation of response magnitude predominantly to presynaptic factors. For example, there might be a temporary depletion of available transmitter, although this appears unlikely since a differential vesicle distribution at synaptic zones of the type II hair cell across the crista has not been described in any species, or a yet undefined nonlinearity in hair cell transduction mechanisms associated with these afferents to hair bundle deflection. As argued above, another possibility presynaptic to the hair cell relates to likely nonuniform cupular motion across the length of the crista (Hillman and McLaren, 1979; McLaren and Hillman, 1979). High-gain and acceleration afferents supply the more middle and central crista (Boyle and Highstein, 1986), where the hair cells are presumably covered by the more mobile portions of the cupula (Hillman and McLaren, 1979). This may account in part for the higher response sensitivities observed in thesc affercnts than in the low-gain afferents for low-amplitude, high-frequency rotations. The kinocilium and longer stereocilia of central hair cells are fairly stiff and extend almost $100 \mu \mathrm{m}$ into channels within the cupula (personal observations); this may provide a stimulus-dependent (nonstatic) nonlinearity of the cupula-ciliary complex and underlie the distortion observed in these afferents for large input magnitudes.

In the following paper (Boyle and Highstein, 1990) we describe the effects of activation of the efferent vestibular system on the afferents' background discharge and rotational responses. Because activation of efferent neurons raises the afferent's rate both at rest and during head movement, efferent activation might serve to increase the bidirectionality or dynamic range of afferents silenced by rotation in the off-direction. For example, the high-gain and acceleration afferents with very low rates will obviously have asymmetric responses to ramps and higher-amplitude sine waves, and these afferents are most strongly affected by efferent vestibular stimulation.

Attempts at modeling the afferent response with a single input-output transfer function could not account for the diverse responses seen. Our afferent classification scheme was useful in describing the response data, but it does not specify unique populations of fibers, since the individual transfer functions of the afferents fell more along a continuum (see Fig. 2). Despite the reduced morphological complexity of the fish's crista compared with their mammalian counterparts (see introductory remarks), individual afferents are under the influence of different synaptic drives for a given head movement, perhaps as a result of regional differences in cupula-endolymph-ampullary wall dynamics. There may also be extensive diversification of action in the various hair cell-afferent complexes.

A first-order, low-pass filter (re: acceleration) was observed in the frequency response of the individual afferents, although
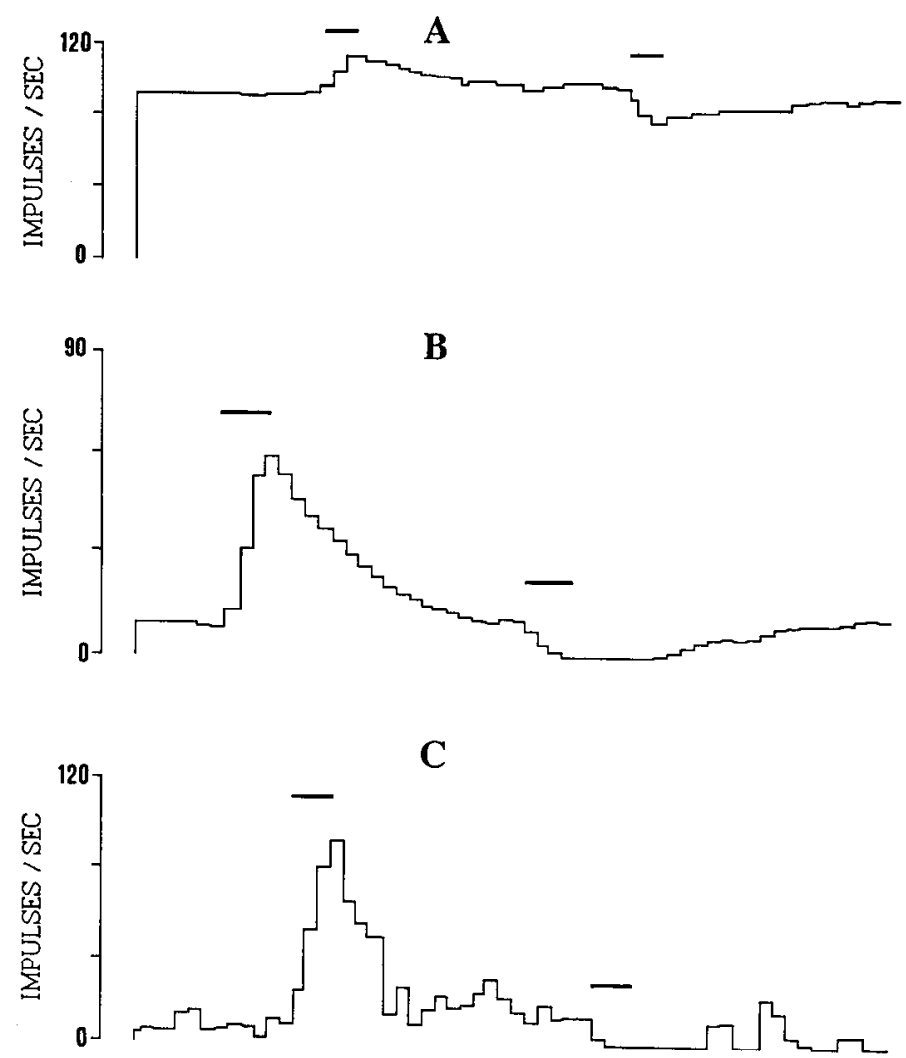

Figure 12. Response of a low-gain $(A)$, high-gain $(B)$, and acceleration (C) afferent to $60 \% \mathrm{sec}$ constant velocity trapezoid. Horizontal bars above each histogram are the 5 -sec period of constant $\left(12 \% \mathrm{sec}^{2}\right)$ acceleration and deceleration.

this was less obvious in the group of acceleration fibers (transfer function indicated by the dotted curve in Fig. 6D). The range of $\tau_{1}$ of low- and high-gain afferents was broad, from 2.7 to 30.1 sec (mean $10.8 \pm 7.4 \mathrm{sec} ; n=53$ ) and compares well to only the $\tau_{1}$ data of the pigeon anterior canal afferents (range 4.45$22.17 \mathrm{sec}$, mean $10.2 \mathrm{sec}$; Landolt and Correia, 1980). In other species studied the mean $\tau_{1}$ is less, roughly 3-6 sec (Fernandez and Goldberg, 1971; Blanks et al., 1975; Blanks and Precht, 1976; Hartmann and Klinke, 1980; Baird et al., 1988). The reason for these differences in $\tau_{1}$ may depend in part on speciesspecific canal geometry (Jones and Spells, 1963) and fluid dynamics and, as mentioned above, cupula-ciliary mechanics. In our population only the response of low-gain afferents (up to 5 $\mathrm{Hz}$ ) could be suitably fit solely by the first-order lag operator. Although the $\tau_{1}$ values differ, the response behavior of low-gain afferents resembles that recently described for regular afferents in the chinchilla (Baird et al., 1988). Between 5 and $10 \mathrm{~Hz}( \pm 5 \%$ sec) no response modulation could be detected in low-gain afferents, and clearly larger amplitudes than were technically possible are necessary to more fully characterize these afferents.

The response behavior of high-gain afferents at frequencies $>0.5 \mathrm{~Hz}$ required additional operations to fit the data. At this frequency the response dynamics of some canal afferents in other species (e.g., squirrel monkey: Fernandez and Goldberg, 1971; goldfish: Hartmann and Klinke, 1980; chinchilla: Baird et al., 1988) also show the influence of high-pass filtering creating the phase advance and gain increase. In our description of highgain afferents 2 transfer functions were suggested (Fig. 6, B, C). 
Considering the first description which was proposed by Fernandez and Goldberg (1971) for the squirrel monkey, a lead operator, governed by the time constant $\tau_{\mathrm{v}}$, was added to a second-order torsion pendulum (Steinhausen, 1931). In this form the high-gain afferents had mean values $\tau_{1}=5.0 \mathrm{sec}$ and $\tau_{\mathrm{v}}=$ $0.096 \mathrm{sec}$, and compare to mean values $\tau_{1}$ and $\tau_{v}$ of $5.7 \mathrm{sec}$ and $0.049 \mathrm{sec}$ in the squirrel monkey (Fernandez and Goldberg, 1971) and $2.91 \mathrm{sec}$ and $0.097 \mathrm{sec}$ in the goldfish (Hartmann and Klinke, 1980), respectively. More recently the adaptation and high-frequency response of canal afferents have been modeled using the Laplace term $s^{k}$ involving the $k$ th power of frequency, where $k$ is a noninteger between 0 and 1 (or fractional order). Thorson and Biederman-Thorson (1974) treated this power law behavior in their review of sensory adaptation as a series of weighted summations over a range of exponential relaxation processes, and Landolt and Correia (1980) provide a detailed description of this operation in their study of the pigeon anterior canal afferents. The reader is referred to the latter study for a more comprehensive discussion of the $s^{k}$ operator as a form of adaptation in the labyrinth. The linear minimum-phase transfer function $s^{\mathrm{k}}$ was amended to $(s+\text { constant })^{\mathrm{k}}$ and applied to the frequency data of the high-gain afferents (Fig. $6 \mathrm{C}$ ). The mean filters value of $k$ was 0.54 , and compares to 0.24 (range $0.017-$ 0.66 ) in the pigeon (Landolt and Correia, 1980) and the range of $k$ values of $0.056-0.49$ in a recent study in the chinchilla (Baird et al., 1988).

Acceleration afferents appear to be exceptional to fish, as they are present in the toadfish and can be seen in data obtaincd from goldfish (Hartmann and Klinke, 1980), but have not been described in higher vertebrates. At first glance these afferents were the simplest to model. An accelerometer approximated their responses over the tested stimulus frequencies. However, a velocity-sensitive component over the middle frequencies creating a phase lag re: acceleration and a flattening of the sensitivity curve (re: stimulus velocity) could be detected. Setling the low-pass filter $\left(\tau_{1}\right)$ equal to that observed for the high-gain afferents and applying the lead element $\tau_{v} s+1$ provided a better model fit to the response data. The $1.25-\mathrm{sec}$ value of $\tau_{\mathrm{v}}$ partially nulls the action of the lag element and a value $>1$ prevents the corner frequency. However, clearly other terms, operating in both the low- and high-frequency stimulus range, would be required to match their peculiar response behavior.

Our data demonstrate that a population of toadfish horizontal semicircular canal afferents signal head velocity at roughly a decade below that of other species, including birds and mammals. Thus, even at a frequency of $0.005 \mathrm{~Hz}$ some low-gain afferents already exhibit velocity sensitivity. This is probably because of the demands of the fish's aquatic environment necessitating the ability to perceive self or imposed motion at these low frequencies. These low-gain, velocity-sensitive afferents presumably innervate, at least in part, relay neurons in vestibuloocular reflex (VOR) pathways providing the necessary transfer function to drive the VOR. (Low-gain afferents may also project into other central pathways.) High-gain, velocity-sensitive afferents are comparable to their primate counterparts exhibiting a more narrow bandwidth for velocity sensitivity. Acceleration afferents are unique to the fish and can respond vigorously to head displacements of less than $1^{\circ}$. High-gain, velocity- and acceleration-sensitive afferents may be the vestibular input necessary for fast spinal reflexes. Thus these 3 groups of afferents provide the toadfish central nervous system with an appropriately broad spectrum of head-movement-related information.
Activation of the efferent vestibular system affects these 3 afferent groups differentially. These efferent vestibular effects form the basis for the following report (Boyle and Highstein, 1990).

\section{References}

Baird RA, Desmadryl G, Fernandez C, Goldberg JM (1988) The vestibular nerve of the chinchilla. II. Relation between afferent response properties and peripheral innervation patterns in the semicircular canals. J Ncurophysiol 60:182-203.

Blanks RHI, Precht W (1976) Functional characterization of primary vestibular afferents in the frog. Exp Brain Res 25:369-390.

Blanks RHI, Estes MS, Markham CH (1975) Physiologic characteristics of vestibular first order canal neurons in the cat. II. Response to constant angular acceleration. J Neurophysiol 38:1250-1268.

Boyle R, Highstein SM (1986) Morphological correlates of physiological properties of horizontal semicircular canal afferents in the toadfish, Opsanus tau. Soc Neurosci Abstr 12:254.

Boyle R, Highstein SM (1990) Efferent vestibular system in the toadfish: action upon horizontal semicircular canal afferents. J Neurosci 10:1570-1582.

Fernandez C, Goldberg JM (1971) Physiology of peripheral neurons innervating semicircular canals of the squirrel monkey. II. Response to sinusoidal stimulation and dynamics of peripheral vestibular system. J Neurophysiol 34:661-675.

Goldberg JM, Fernandez C (1971) Physiology of peripheral neurons innervating semicircular canals of the squirrel monkey. I. Resting discharge and response to constant angular accelerations. J Neurophysiol 34:635-660.

Goldberg JM, Fernandez C (1977) Conduction times and background discharge of vestibular afferents. Brain Res 122:545-550.

Goldberg JM, Smith CE, Fernandez C (1984) Relation between discharge regularity and responses to externally applied galvanic currents in vestibular nerve afferents of the squirrel monkey. J Neurophysiol 51:1236-1256.

Hartmann R, Klinke R (1980) Discharge properties of afferent fibres of the goldfish semicircular canal with high frequency stimulation. Pflucgers Arch 388:111-121.

Highstein SM, Politoff AL (1978) Relation of interspike baseline activity to the spontaneous discharges of primary afferents from the labyrinth of the toadfish, Opsanus tau. Brain Res 150:182-187.

Hille B (1984) Ionic channels of excitable membranes, pp 1-426. Sunderland, MA: Sinauer.

Hillman DE (1974) Cupular structure and its receptor relationship. Brain Behav Evol 10:52-68.

Hillman DE (1977) Relationship of the sensory cell cilia to the cupula. Scan Elec Microscopy 2:415-420.

Hillman DE, McLaren JW (1979) Displacement configuration of semicircular canal cupulae. Neuroscience 4:1989-2000.

Honrubia V, Hoffman LF, Sitko S, Schwartz IR (1989) Anatomic and physiologic correlates in bullfrog vestibular nerve. J Neurophysiol 61: 688-701.

Jones GM, Spells KE (1963) A theoretical and comparative study of the functional dependence of the semicircular canal upon its physical dimensions. Proc R Soc Lond Ser B 157:403-419.

Keller EL (1976) Behavior of horizontal semicircular canal afferents in alert monkey during vestibular and optokinetic stimulation. Exp Brain Res 24:459-471.

Kernell D (1968) The repetitive impulse discharge of a simple neurone model compared to that of spinal motoneurones. Brain Res 11:685687.

Kitch RD, Highstein SM (1987) Central projections of the primary octavolateralis afferents in the toadfish. Soc Neurosci Abstr 13:133.

Landolt JP, Correia MJ (1980) Neurodynamic response analysis of anterior semicircular canal afferents in the pigeon. J Neurophysiol 43: 1746-1762.

Landolt JP, Correia MJ, Young ER, Cardin RPS, Sweet RC (1975) A scanning electron microscopic study of the morphology and geometry of neural surfaces and structures associated with the vestibular apparatus of the pigeon. J Comp Neurol 159:257-288.

Louie AW, Kimm J (1976) The response of 8th nerve fibers to horizontal oscillations in the alert monkey. Exp Brain Res 24:447-457.

Lowenstein O, Sand A (1940) The mechanism of the semi-circular canals: a study of responses of single fiber preparations to angular 
acceleration and to rotation at constant speed. Proc R Soc Lond Ser B 129:256-275.

McLaren JW, Hillman DE (1979) Displacement of the semicircular canal cupula during sinusoidal rotation. Neuroscience 4:2001-2008.

O'Leary DP, Honrubia V (1976) Analysis of afferent responses from isolated semicircular canal of guitarfish using rotational accclcration white-noise inputs. II. Estimation of linear systems parameters and gain and phase spectra. J Neurophysiol 39:645-659.

O'Leary DP, Dunn RF, Honrubia V (1976) Analysis of afferent responses from isolated semicircular canal of the guitarfish using rotational acceleration white-noise inputs. J Neurophysiol 39:631-644.

Precht W, Llinas R, Clarke M (1971) Physiological responses of frog vestibular fibres to horizontal angular rotation. Exp Brain Res 13: 378-407.

Cajal Ramón y S (1908) Sur un noyau special du nerf vestibulaire des poissons et des oiseaux. Trav Lab Rech Biol Univ Madrid 6:1-20.

Schessel DA (1982) Chemical synaptic transmission between type I vestibular hair cells and the primary afferent nerve chalice: an intra- cellular study utilizing horseradish peroxidase, Albert Einstein Coll Med, Bronx, NY: Ph.D. dissertation, pp 1-85.

Segal BN, Outerbridge JS (1982) Vestibular (semicircular canal) primary neurons in bullfrog: nonlinearity of individual and population response to rotation. J Neurophysiol 47:545-562.

Scidcl RC (1975) Transfer-function-parameter estimation from frequency response data-a FORTRAN program. NASA Technical Memorandum, NASA TM X-3286.

Steinhausen W (1931) Uber den Nachweis der Bewegung der Cupula in der intakten Bogengansampulle des Labyrinths bei der naturlichen rotatorischen und calorischen Reizung. Pfluegers Arch Ges Physiol 228:322-328.

Thorson J, Biederman-Thorson M (1974) Distributed relaxation processes in sensory adaptation. Science 183:161-172.

Yagi T, Simpson NE, Markham CH (1977) The relationship of conduction velocity to other physiological properties of the cat's horizontal canal neurons. Exp Brain Res 30:587-600 